\title{
Reduced Order Observer Based Load Frequency Control Using Pole-Placement Design
}

\author{
${ }^{1}$ Lod Tapin, ${ }^{2}$ Pagge Rime, ${ }^{3}$ Dr. Ram Krishna Mehta \\ ${ }^{1,2,3}$ NERIST, Arunachal Pradesh, India
}

\begin{abstract}
In a power system, as a power load demand varies randomly, both area frequency and line power also vary. The objectives of load frequency control (LFC) are to minimize the transient deviations in these variables (area frequency and line power) and to ensure their steady state errors to be zeros. When dealing with the LFC problem of power systems, unexpected external disturbances, parameter uncertainties and the model uncertainties of the power system pose big challenges for controller design.

In this project, a reduced-order state observer with a practical point of view for LFC problem in a power system is proposed based on the pole-placement method. A proper choice of closed-loop pole location has been proposed using symmetrical root locus (SRL) method. In the practical environment, there is limited access to all state variables of system and measuring all of them is usually impossible. So when the available sensors are less than the number of states or when it may be undesirable, expensive or impossible to measure directly all of the states, a reduced-order state observer can be applied as proposed in this project. The proposed strategy is tested on a single area power system. The dynamic model of the power system and the controller design based on the model are elaborated. The robustness and stability of the control schemes is examined through simulations.
\end{abstract}

Keywords: Load Frequency Controller, Power system, Reduced Order Observer, Integral controller and SRL.

\section{Introduction}

[1] Frequency regulation is necessary to control the flow of alternating current power from multiple generators through the network. The change in system frequency provides a measure of mismatch between demand and generation, and thus is a necessary parameter for load control. Frequency changes are an unavoidable consequence of changing demand. Rapidly changing mains frequency is often a sign that a distribution network is operating close to its capacity limits, dramatic examples of which can be observed just before major power outages. During an overload caused by the failure of generators or transmission lines, the power system frequency will decline, due to an imbalance of load versus generation. On the other hand, the sudden loss of an interconnection, while exporting power will cause the system frequency to rise.

[2] A state observer estimates the state variables based on the measurements of the output and control variables. A state Observer can be designed if and only if the observability condition is satisfied. A state vector $\mathrm{x}$ is an $\mathrm{n}$ vector and the output vector $\mathrm{y}$ is an $\mathrm{m}$-vector that can be measured. Here, m-state variables need not be estimated. We need to estimate only $n-m$ state variables.

[3]-[4] The state observation problem has been widely studied since the original works of Kalman and Luenberger. In this respect, many papers aim at designing reduced-order observers, which provide an estimate of a linear functional of the state.

[5] In this paper a reducer order observer is analyzed for so-called generalized state space (or descriptor) systems. Based on the staircase form for generalized stair space models. A recursive algorithm is presented to construct a reduced order observer for a given observable description system.

[6] This paper presents a reduced-order estimator by using an LQR regulator with a prescribed degree of

Stability for two-area load frequency control problem in a deregulated power system. It shows that the load frequency control requirements in a practical environment are satisfied and also with so good dynamic responses, sensitivity to plant-parameter variations is reduced.

[7] One major approach to achieve a better system performance is through the closed loop pole placement using Symmetrical Root Locus (SRL). In this method, the poles of closed loop system can be placed arbitrarily at any locations in the complex plane.

[10] Also, the LFC problem is very important in interconnected power system because the load perturbation in any areas disturb the frequency of others. 
The paper is organized as follows. Section I presents introduction to LFC. Section II presents modeling of major components of power system. Section III presents the proposed model. Section IV shows the simulation results of our plant with parameters uncertainty. Section V Conclusion and references of our generated plant stability is discussed.

\section{Power System Model}

The first step in analysis and design of a control system is mathematical modeling of the system. The modeling of various components of LFC is done by using transfer function approach [9] suggested simple modeling of governor, turbine \& power system parts of LFC and putting dynamic model in state variable form.

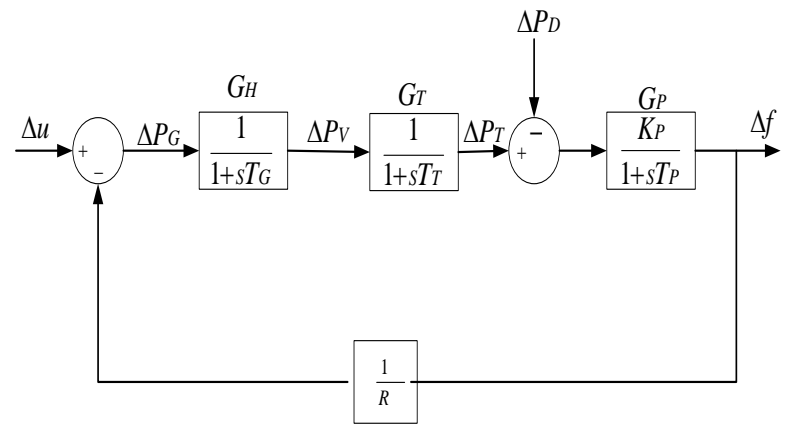

Figure 1: Primary ALFC loop

We use three state variables $x_{1}, x_{2}$ and $x_{3}$ forming the state vector

$$
\begin{gathered}
X=\left[\begin{array}{l}
x_{1} \\
x_{2} \\
x_{3}
\end{array}\right] \square\left[\begin{array}{c}
\Delta P_{V} \\
\Delta P_{T} \\
\Delta f
\end{array}\right] \\
{\left[\begin{array}{c}
\dot{x}_{1} \\
\dot{x_{2}} \\
\dot{x_{3}}
\end{array}\right]=\left[\begin{array}{ccc}
\frac{-1}{T_{H}} & 0 & \frac{-1}{R T_{H}} \\
\frac{1}{T_{T}} & \frac{-1}{T_{T}} & 0 \\
0 & \frac{K_{P}}{T_{P}} & \frac{-1}{T_{P}}
\end{array}\right]\left[\begin{array}{c}
x_{1} \\
x_{2} \\
x_{3}
\end{array}\right]+\left[\begin{array}{c}
\frac{1}{T_{H}} \\
0 \\
0
\end{array}\right] u+\left[\begin{array}{c}
0 \\
0 \\
\frac{-K_{P}}{T_{P}}
\end{array}\right] \Delta P_{D}}
\end{gathered}
$$

In more compact form,

$$
\dot{X}=A x+B u+\Gamma \Delta P_{D}
$$

This chapter has laid the groundwork for both the controller design and the constructions of the power systems.

\section{Proposed Model}

[2] It is well known that to minimize frequency variations, a large proportional feedback gain is desirable. To show how to construct and estimate of the state vectors using the system inputs and outputs, we consider our proposed system governed by

$$
\begin{aligned}
& \dot{\boldsymbol{X}}=A x+B u \\
& \dot{y}=C X
\end{aligned}
$$

And the observer designed for the free system can be used if the input is connected to the observer

$$
\check{z}=D z+C x+G u
$$


After analysis it is found that $\wedge$

$$
x_{1}(s)=a_{01} x_{3}(s)+a_{02} u(s)
$$

$$
x_{2}(s)=a_{03} x_{3}(s)+a_{04} u(s)
$$

The above equations can be framed into model as shown below in Figure [2]

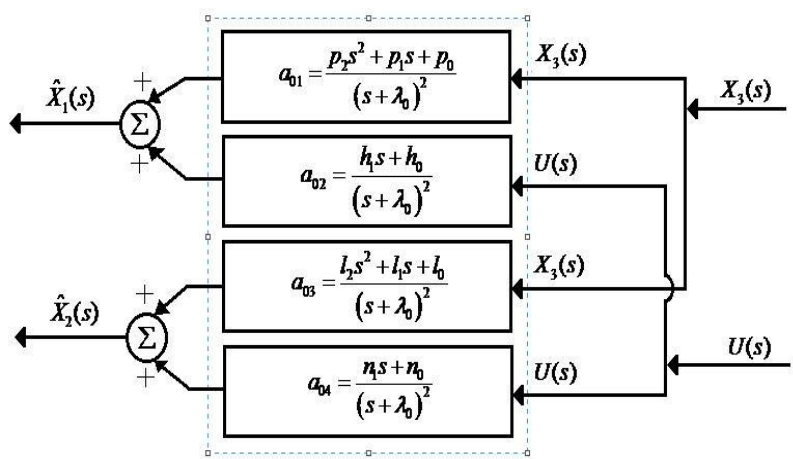

Figure 2: Design of Reduced Order Observer with its Derived Parts.

Where,

$p_{2}=-h_{11}$

$p_{1}=m_{11}-h_{11} r_{1}$

$p_{0}=m_{11} \boldsymbol{r}_{1}-m_{12} \boldsymbol{r}_{0}-h_{11} \boldsymbol{r}_{0}$

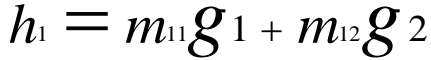

$h_{0}=m_{11} g_{2}+m_{11} g_{1} r_{1}-m_{12} g_{1} r_{0}$

$l_{2}=-h_{21}$

$l_{1}=m_{21}-h_{21} r_{1}$

$l_{0}=m_{21} \boldsymbol{r}_{1}-m_{22} \boldsymbol{r}_{0}-h_{21} \boldsymbol{r}_{0}$

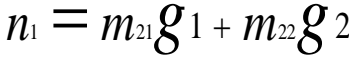

$n_{0}=m_{21} g_{2}+m_{21} g_{1} r_{1}-m_{22} g_{1} r_{0}$

Now Fig [2] can be implemented as full state feedback based reduced observer with integral controller scheme for LFC as shown in Figure [3]

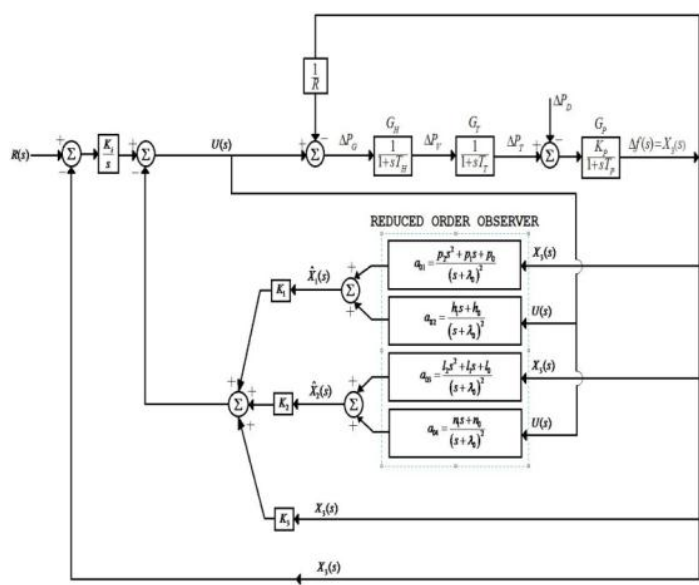

Figure 3: Proposed Reduced Order Observer Model 
The control input $\mathrm{U}(\mathrm{s})$ which is directly related to actuator and it tries to rotate the motor thus the speed changer which provides upward and downward vertical movements proportional to the change in speed. The control input sets the integrator pole ( $\rho \mathrm{i})$ and the closed loop pole ( $\rho 0)$ values. The value of integrator pole is selected as 600 with trial and error method which gives closed loop pole range $0<\mathrm{Po}<24$. We will set $\rho i=600$ and $\rho o=8$ as specified value for the proposed model. Now we will check for its stability in two cases, before and after the integral controller at the given $\rho$ i and $\rho$ value.

\section{Selection Of Closed-Loop Poles}

[11] The Symmetric Root Locus used in this project is to provide a basis for specifying closed-loop poles in pole-placement design. The SRL equation is described as

$$
1+\rho G(s) G(s)=0
$$

Here, $\rho_{\mathrm{i}}$ is set at large value of 600 to reduce the control effort. The gain matrices that places the closed loop poles at the stable roots of SRL are evaluate in TABLE [1] using parameters given in TABLE [2]. The SRL equation helps in the calculation, location and behavior of the system poles by proper choice of $\rho_{\mathrm{i}}$.

TABLE 1: GAIN VALUES AT $\rho_{\mathrm{i}=600} \& \rho_{0=8}$
\begin{tabular}{|c|c|}
\hline GAIN & VALUE \\
\hline Ki & 195.988673142098 \\
\hline K1 & 2.52415578965696 \\
\hline K2 & 20.6438888058237 \\
\hline K3 & 46.0849611539983 \\
\hline
\end{tabular}

The closed loop eigenvalues of the system are

$$
\begin{aligned}
& \lambda_{0}=-9.6846 \\
& \lambda_{1}=-9.6846 \\
& \lambda_{2}=-20.0660
\end{aligned}
$$

Since we can select the observer eigenvalues $r_{0}, r_{1}$ and $r_{2}$ from 3 to 7 times of system poles. So, we will select observer poles 3 times of system poles for our proposed model.

\section{Stability Margins}

In this section, two break points $X_{1}$ and $X_{2}$ from Figure [3] are considered. $X_{1}$ is provided after the integral controller $(\mathrm{Ki})$ and the required Gain Margin $\left(\mathrm{GM}_{1}\right)$ and Phase Margin $\left(\mathrm{PM}_{1}\right)$ are determined using TABLE [2]. The open loop transfer function $\mathrm{Gx}_{1}(\mathrm{~s})$ of this system is determined as

$G \times 1(S)=\frac{N_{1} s^{3}+N_{2} s^{2}+N_{3} s+N_{4}}{D_{1} s^{6}+D_{2} s^{5}+D_{3} s^{4}+D_{4} s^{3}+D_{s} s^{2}+D_{6} s^{1}+D_{7}}$

Where,

$N_{1}=R K_{P} A 6$

$N_{2}=R K P A 6$

$N_{3}=R K P A 6$

$N_{4}=R K P A 6$

$D_{7}=0$

Using above expression it is found that the Gain Margin and Phase Margin at $\rho \mathrm{i}=600$ and $\rho 0=8$ are 12.4db and 30.5 Degree respectively. Fig [4] shows bode-plot for $\rho i=600$ and $\rho o=18$ using Equ. [10] 
Similarly, the break point $\mathrm{X}_{2}$ is provided before the integral controller and the required Gain Margin $\left(\mathrm{GM}_{2}\right)$ and Phase Margin $\left(\mathrm{PM}_{2}\right)$ are determined using TABLE [2]. The open loop transfer function $\mathrm{Gx}_{2}(\mathrm{~s})$ of this system can be determined as

$$
G \times 2(S)=\frac{N_{1} s^{2}+N_{2} s+N_{3}}{D i s^{6}+D_{s} s^{5}+D_{s} s^{4}+D s s^{3}+D s s^{2}+D s s^{1}+D}
$$

Where,

$$
\begin{aligned}
& N_{1}=k i K_{P} R \\
& N_{2}=k i K P R r_{1} \\
& N_{3}=k i K P R r_{0} \\
& D_{7}=0
\end{aligned}
$$

Similarly, Using above expression it is found that the Gain Margin and Phase Margin at $\rho \mathrm{i}=600$ and $\rho 0$ $=8$ are $11.7 \mathrm{~dB}$ and 15.7 Degree respectively. Fig [5] shows bode-plot for $\rho \mathrm{i}=600$ and $\rho \mathrm{o}=18$ using Equ [11]. In both cases, the system is stable and thus, a necessary and sufficient condition for the system to be stable is fulfilled.

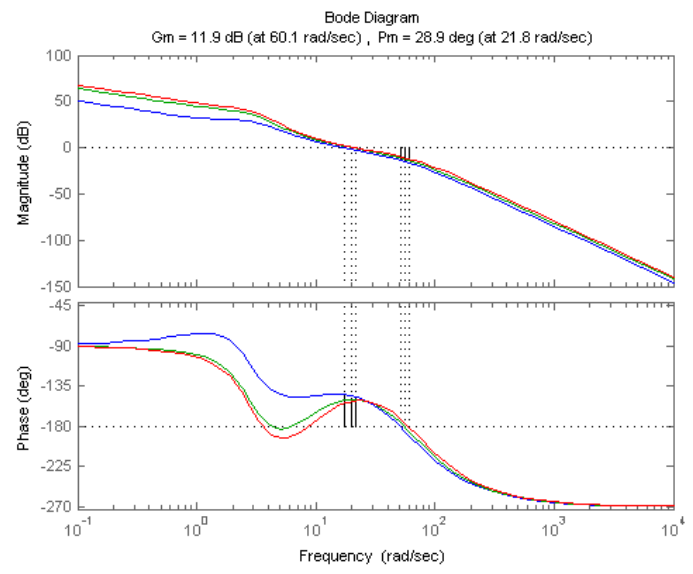

Figure 4: Gx1(s) Bode plot for $\rho \mathrm{i}=600$ and $\rho \mathrm{o}=18$

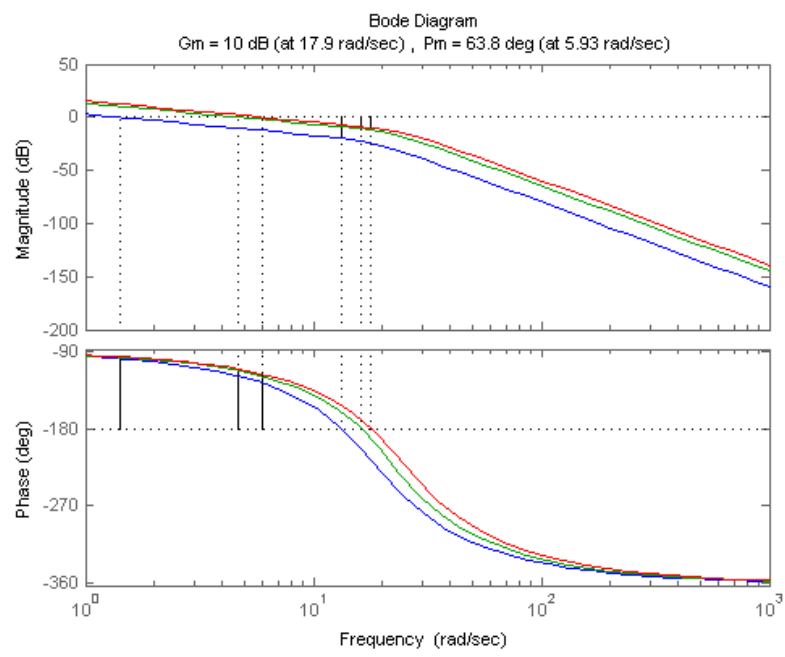

Figure 5: Gx2(s) Bode plot for $\rho i=600$ and $\rho o=18$ 


\section{Simulation}

In the simulation study, the proposed reduced order model is applied for one area power system LFC. To illustrate the performance of this model, simulations are performed for without observer and with observer. In this simulation the performance of the proposed simulations are done using MATLAB [12]. The power system parameters are given in TABLE [2].

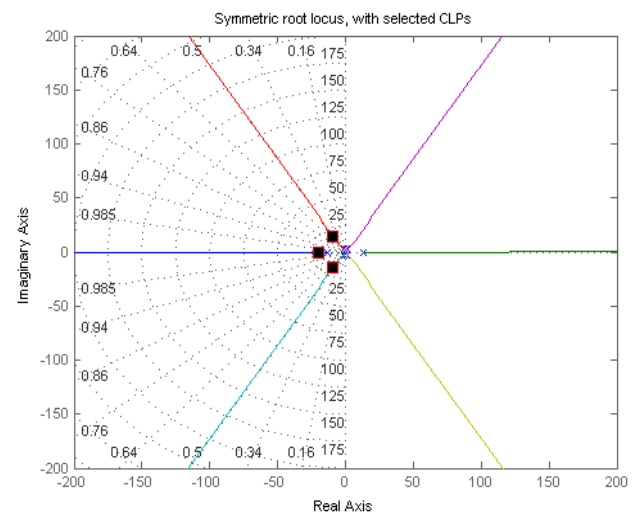

Figure 6: Symmetrical Root Locus

Since $\rho i$ is set at 600 and from SRL the closed-loop poles on the left half plane of jw-axis are considered as our desired closed-loop poles. Thus SRL provides a basis for specifying CLPs in a pole-placement design. All the gain values $\mathrm{K}_{\mathrm{i}}, \mathrm{K}_{1}, \mathrm{~K}_{2}$ and $\mathrm{K}_{3}$ in Figure [3] are determined by SRL and tabulated in TABLE [1].

\section{Without Reduced order Observer}

In this model, observer part is excluded, which means that the output is directly connected to $\mathrm{K}_{\mathrm{i}}, \mathrm{K}_{1}, \mathrm{~K}_{2}$ and $\mathrm{K}_{3}$. The Figure [7] shows the step-Response of state feedback and integral control system.

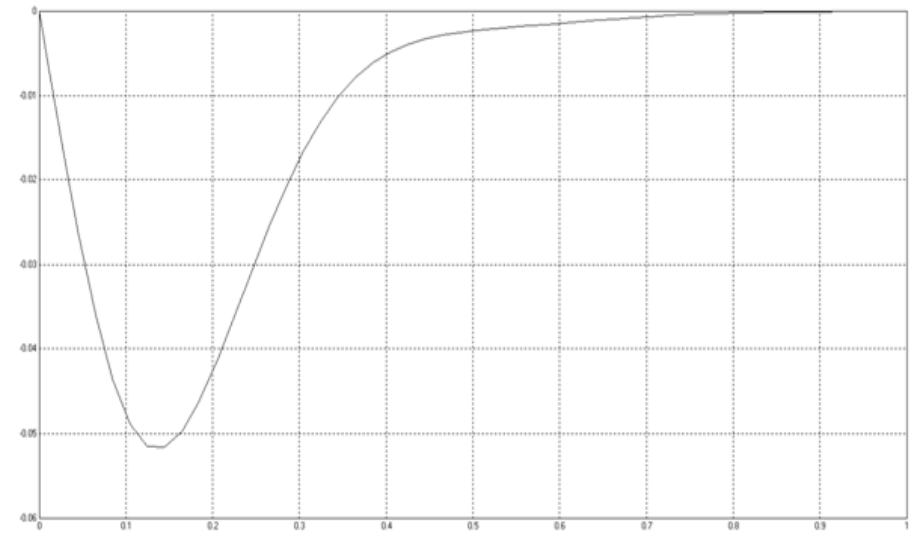

Figure 7: Step-Response without Observer.

\section{Control Input}

The control input $\left(\Delta \mathrm{U} / \Delta \mathrm{P}_{\mathrm{D}}\right)$ which is directly related to actuator and it tries to rotate the motor thus the speed changer which provides upward and downward vertical movements proportional to the change in speed. The control input sets the integrator pole and the closed loop pole values. The required control input transfer function is

$$
\frac{\Delta U(S)}{\Delta P_{D}(S)}=\frac{N_{1} s^{5}+N_{2} s^{4}+N_{3} s^{3}+N_{4} s^{2}+N_{5} S+N_{6}}{D_{1} s^{6}+D_{2} S^{5}+D_{3} s^{4}+D_{4} s^{3}+D_{s} s^{2}+D_{6} s^{1}+D_{7}}
$$


Where,

$N_{1}=R K_{P} G_{1} A_{6}$

$N_{2}=R K P\left(G_{1} A 7+G_{2} A_{6}\right)$

$N_{3}=R K P\left(G_{1} A_{8}+G_{2} A_{7}+A_{6}\right)$

$N_{4}=R K P\left(G_{1} A_{9}+G_{2} A_{8}+A 7\right)$

$N_{5}=R K P\left(G_{2} A 9+A 8\right)$

$N_{6}=R K P A 9$

Using equation [12], the $\rho_{\mathrm{i}}$ is varied in the range between 100-1000. It is interesting to note that our desired value $\rho_{\mathrm{i}}=600$ and closed-loop pole $\rho_{0}=8$ not only gives optimal settling time but also provides balances between the acceptable response and the amount of control energy required. Also, Figure [8] shows that the peak and peak time is acceptable at $\rho_{\mathrm{i}}=600$ which gives optimal control approach and provides optimal speed of response which requires smaller actuator and thus low cost.

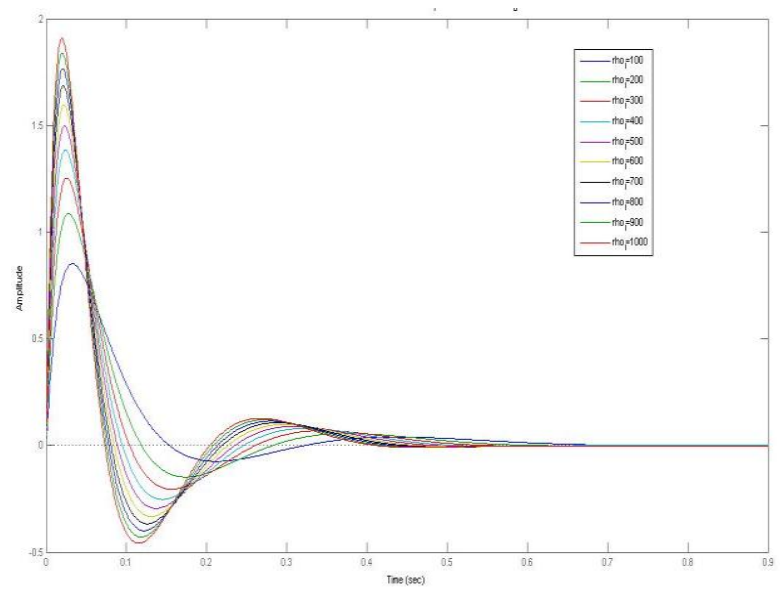

Figure 8: Control Input $\Delta \mathrm{u}$ Plot for different $\rho_{\mathrm{i}}$

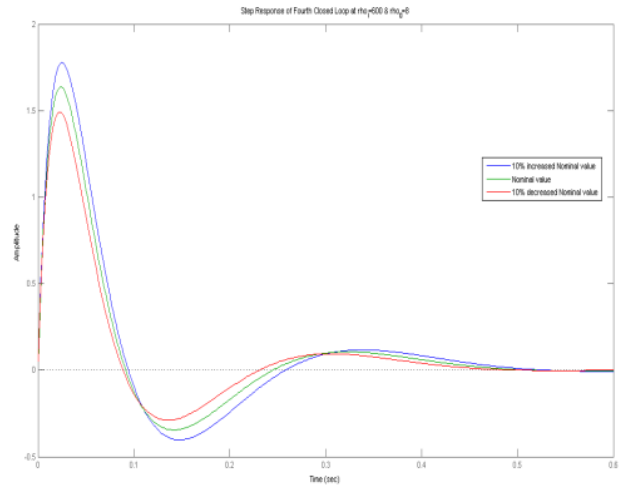

Figure 9: $\Delta \mathrm{u}$ Plot for $₫ 10 \%$ Nominal Value change.

\section{Closed-Loop System of the proposed model $\Delta \mathbf{f} / \Delta \mathbf{P}_{\mathrm{D}}$}

The step response of our model with reduced order observer is shown here. Figure [10] shows different responses for varying $\rho_{0}$ and fixed $\rho_{\mathrm{i}}$. It shows that the settling time required for the system which gives small transient amplitude is 4.37 seconds which is minimum settling time when we vary $\rho_{0}$ from 1-25 keeping $\rho \mathrm{i}=600$. Step-Response of proposed model at $₫ 10 \%$ Nominal Value using TABLE [2] is also shown in Figure [11]. Besides, Fig [12] and Fig [13] shows identical output of proposed model using matlab program and simulink model. 


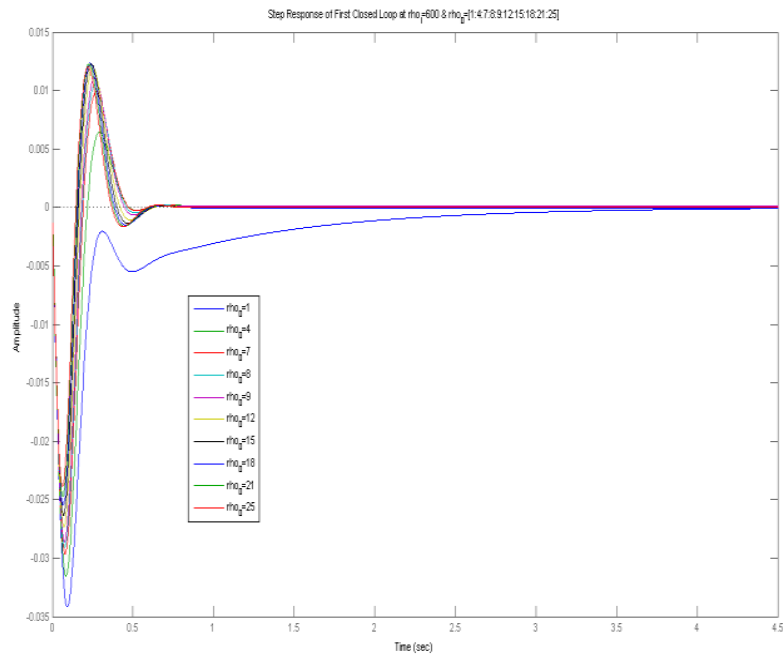

Figure 10: $\Delta \mathrm{f}$ Plot of model for different $\rho_{0}$

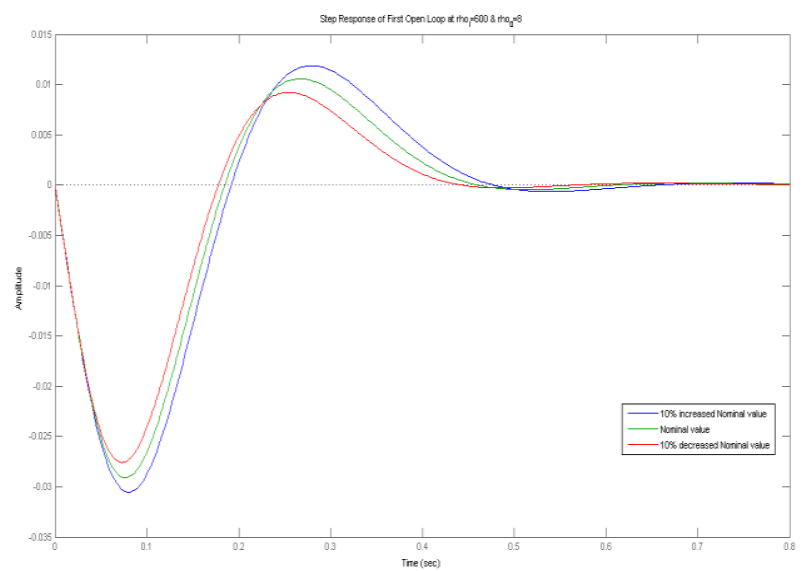

Figure 11: $\Delta \mathrm{f}$ Plot for $₫ 10 \%$ Nominal Value change

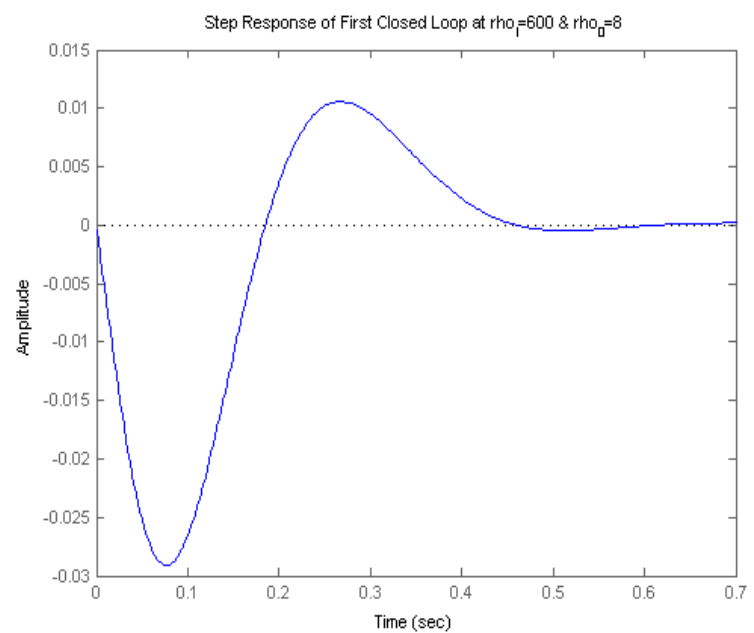

Figure 12: Step Response of $\Delta \mathrm{f} / \Delta \mathrm{P}_{\mathrm{D}}$ at $\rho \mathrm{i}=600 \& \rho 0=8$ by matlab program. 


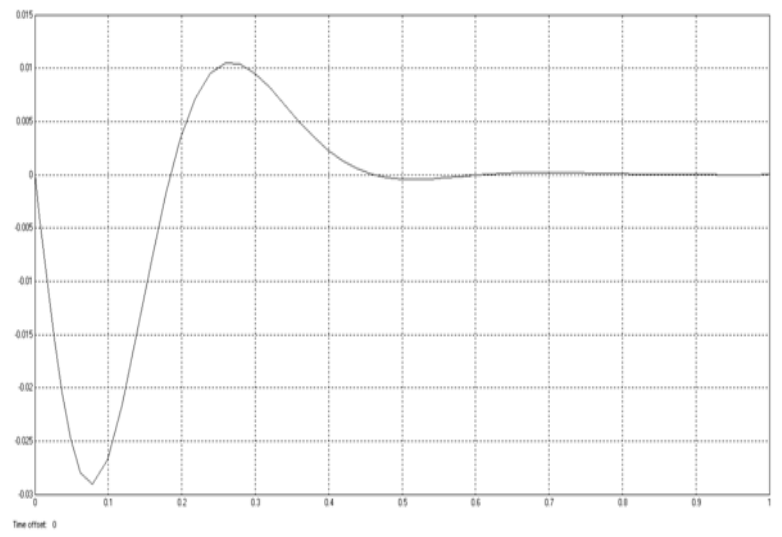

Figure 13: Step Response of $\Delta \mathrm{f} / \Delta \mathrm{P}_{\mathrm{D}} \rho \mathrm{i}=600 \& \rho 0=8$ by simulink.

\section{Simulink Model and Estimation of States}

Final simulink model of our proposed Reduced-Order Observer is shown in Fig [14]. Now using simulink model, we will compare the dynamic response of change in turbine power $\Delta \mathrm{P}_{\mathrm{T}}$ and change in valve power $\Delta \mathrm{P}_{\mathrm{V}}$

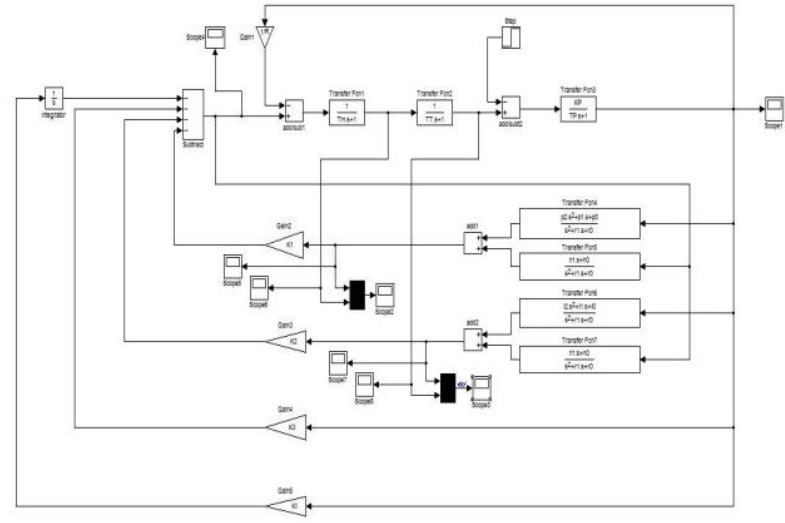

Figure 14: Reduced Order Observer simulink model.

Fig [15] and Fig [16] shows how the observer estimates the dynamic response of the system. The response pattern of the original response and the estimated response in Fig [15] and Fig [16] are nearly same but are slightly differ as there exist very small error between them which indicate that the estimated value will not be exactly like the original value. Therefore, the proposed control scheme shows the ability to measure all the states. Thus, the requirement of mechanical sensors is eliminated and reduces cost effects.

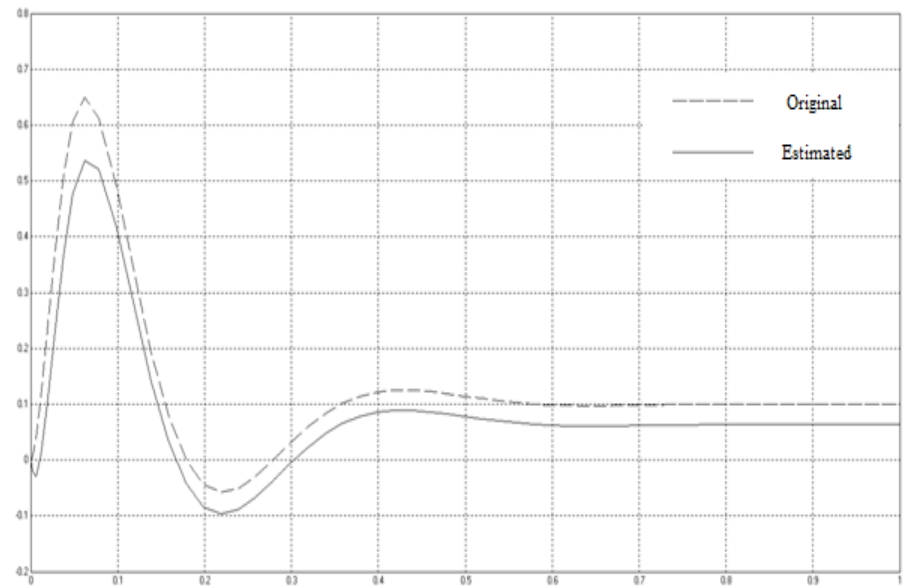

Figure 15: comparison of original $\Delta \mathrm{P}_{\mathrm{V}}$ and estimated $\Delta \mathrm{P}_{\mathrm{V}}$ in simulink. 


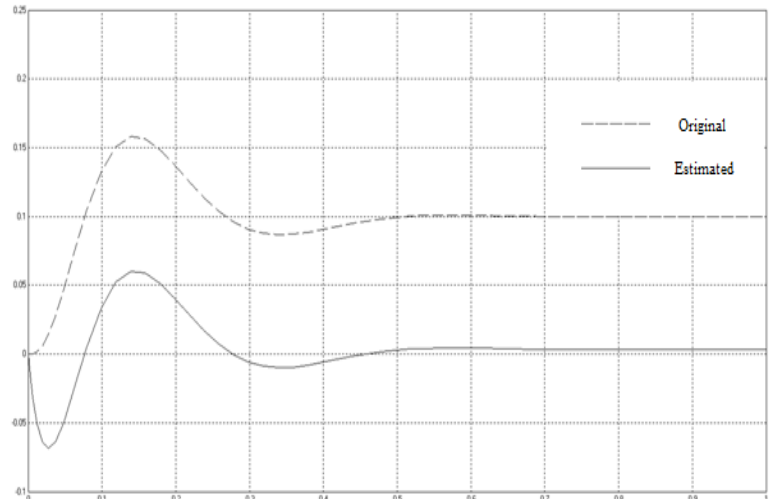

Figure 16: comparison of original $\Delta \mathrm{P}_{\mathrm{T}}$ and estimated $\Delta \mathrm{P}_{\mathrm{T}}$ in simulink.

\section{Conclusion}

In this paper, the capability of estimating the unmeasurable states using Reduced-Order Observer with integral control has been presented. The simulation results verified the effectiveness, stability and robustness of proposed strategy under parameter variations and external disturbances. Besides, the cost factor is reduced due to elimination of mechanical sensors.

Table 2: Turbine And Governor System Parameters Lfc

\begin{tabular}{|c|c|c|c|c|c|}
\hline & $\begin{array}{c}\mathrm{Kp} \\
(\mathrm{pu} / \mathrm{Hz})\end{array}$ & $\begin{array}{c}\mathrm{T}_{\mathrm{P}} \\
(\mathrm{s})\end{array}$ & $\begin{array}{c}\mathrm{T}_{\mathrm{T}} \\
(\mathrm{s})\end{array}$ & $\begin{array}{c}\mathrm{T}_{\mathrm{H}} \\
(\mathrm{s})\end{array}$ & $\begin{array}{c}\mathrm{R} \\
(\mathrm{Hz} / \mathrm{pu})\end{array}$ \\
\hline$+10 \%$ & 132 & 22 & 0.33 & 0.088 & 2.64 \\
\hline Nominal & 120 & 20 & 0.3 & 0.08 & 2.64 \\
\hline$-10 \%$ & 108 & 18 & 0.27 & 0.072 & 2.16 \\
\hline
\end{tabular}

\section{NOMENCLATURE}

$\mathrm{R} \quad$ Droop Characteristics $(\mathrm{Hz} / \mathrm{pu})$

$\Delta \mathrm{f} \quad$ Change in frequency $(\mathrm{Hz})$

$\Delta \mathrm{P}_{\mathrm{G}} \quad$ Change in generator power (MW)

$\Delta \mathrm{P}_{\mathrm{V}} \quad$ Change in valve power (MW)

$\Delta \mathrm{P}_{\mathrm{T}} \quad$ Change in turbine power (MW)

$K_{P} \quad$ Power system equivalent gain

$\mathrm{T}_{\mathrm{P}} \quad$ Power system equivalent time constant (s)

$\mathrm{T}_{\mathrm{T}} \quad$ Turbine time constant (s)

$\mathrm{T}_{\mathrm{H}} \quad$ Governor Time constant (s)

$\mathrm{X}(\mathrm{t}) \quad$ State vector of order $(\mathrm{nx} 1)$

$\mathrm{Y}(\mathrm{t}) \quad$ Output vector of order (px1)

A System matrix of order (nxn)

B Input matrix of order (nxm)

C Output matrix of order (pxn)

D Transmission matrix of order (pxm)

\section{References}

[1] S Z Sayed Hassen, A robust approach to the load frequency control problem with speed regulation uncertainty, Member, IEEE International Journal of Electronics and Electrical Engineering 62012.

[2] Katsuhiko Ogata, Modern Control Engineering: New Delhi: Prentice-Hall India, Fourth Edition 2002, pp. 497-520, 826-850, 897920.

[3] Kalman, R. E. (1960). A new approach to linear filtering and prediction problems. Transactions of the ASME, Journal of Basic Engineering 82, 34-45.

[4] Luenberger, D. G. (1977). Dynamic equation in descriptor form. IEEE Transactions on Automatic Control AC-22(3), 312-321.

[5] Verhaegen, M. and P. Van Dooren (1986). A reduced order observer for descriptor systems. System \& Control Letters 8(1), 29-37.

[6] E. Rakhshani, and J. Sadeh, "A Reduced-Order Estimator with Prescribed Degree of Stability for Two-Area LFC System in a Deregulated Environment" IEEE Power Engineering Society - PSCE 2009, Washington, USA.

[7] Bo Ling, "State-Feedback Regional Pole Placement via LMI Optimization" Senior Member, IEEE Proceedings of the American Control Conference Arlington, VA June 25-27, 2001

[8] Kailath Linear System, 1980.

[9] O. I. Elgerd, "Control of electric power systems," IEEE Control Syst.Mag., vol. 1, no. 2, pp. 4-16, 1981]

[10] H. Saadat, Power System Analysis, McGraw-Hill , 2002.]

[11] [Kundur, P.'Power system stability and control', McGraw Hill, New York, 1994].

[12] Matlab 2010a software. 